\title{
PENGEMBANGAN MEDIA PEMBELAJARAN PELAKSANAAN DAN PENGAWASAN PEKERJAAN KONSTRUKSI GEDUNG (P3KG) MOBILE LEARNING BERBASIS ANDROID PADA PESERTA DIDIK KELAS XII BISNIS KONSTRUKSI DAN PROPERTI DI SMK NEGERI 1 SINGOSARI
}

\author{
Syahrul Furqon ${ }^{1}$, Mohammad Musthofa Al Ansyorie ${ }^{2}$, Eko Suwarno ${ }^{3}$ \\ Teknik Sipil, Fakultas Teknik,Universitas Negeri Malang \\ Jl. Semarang No.5, Kota Malang, Jawa Timur 65145 \\ (0341) 551-312 \\ E-mail: ${ }^{2}$ foqyrathomy@gmail.com
}

\begin{abstract}
ABSTRAKS
Bedasarkan pengalaman Penulis pada saat menempuh Kajian dan Praktik Lapangan (KPL) di SMK terdapat bahwa peserta didik kurang memahami konsep materi maupun konsep praktikum yang disampaikan oleh Mahasiswa KPL maupun Guru Pamong pada saat kegiatan belajar berlangsung. Selain itu, ketergantungan peserta didik pada smartphone sangat banyak. Namun, penggunaan pada jenjang tersebut lebih cenderung digunakan untuk Hiburan yang dapat menghambat proses pembelajaran peserta didik pada saat sekolah maupun pada saat diluar sekolah. Tujuan penelitian ini adalah menghasilkan Produk Media Pembelajaran Pelaksanaan dan Pengawasan Pekerjaan Konstruksi Gedung (P3KG) Berbasis Mobile Learning untuk Platform Android di SMK Negeri 1 Singosari. Penelitian ini mengunakan metode $R$ \& D yang sudah dimodifikasi oleh penulis. Langkah-lahngah penelitian dan pengembangan ini meliputi, analisis kebutuhan dan pengumpulan data, desain produk, Validasi, Revisi Produk Awal, Pengujian Produk, Produk Jadi. Subjek Penelitian ini adalah siswa kelas XII SMK Negeri 1 Singosari yang berjumlah 34 siswa, ahli materi dari satu Dosen Teknik Sipil Universitas Negeri Malang dan ahli media dari satu Dosen Teknik Sipil Universitas Negeri Malang. Hasil yang diperoleh dari penelitian pengembangan ini adalah media pembelajaran berbasis android pada mata pelajaran Pelaksanaan dan Pengawasan Pekerjaan Konstruksi dan Gedung dengan spesifikasi berisi (1) Halaman Pengantar Aplikasi, (2) Main Menu, (3) Kompetensi, (4) Materi, (5) Video Pembelajaran, (6) Latihan Soal, (7) Panduan Penggunaan, (8) Profil Pengembang. Hasil penelitian untuk uji kelayakan menunjukkan bahwa Pengembangan Media Pembelajaran Pelaksanaan Dan Pengawasan Pekerjaan Konstruksi Gedung (P3KG) Mobile Learning Berbasis Android Pada Peserta Didik Kelas XII Bisnis Konstruksi Dan Properti Di Smk Negeri 1 Singosari ini termasuk dalam klasifikasi cukup valid dan dapat disebarkan.
\end{abstract}

Kata Kunci: R\&D, Android, Aplikasi Android, Mobile Learning, P3KG

\begin{abstract}
Based on the author's experience when taking Field Studies and Practices at SMK, it is found that students do not understand the concept of material and practical concepts delivered by KPL Students and Pamong Teachers during learning activities. In addition, the dependence of students on smartphones is very much. However, the use at this level is more likely to be used for entertainment which can hinder the learning process of students at school and outside of school. The purpose of this research is to produce a learning media product for the implementation and supervision of building construction work based on mobile learning for the Android platform at SMK Negeri 1 Singosari. This study uses an $R \& D$ method that has been modified by the author. These research and development steps include, needs analysis and data collection, product design, validation, initial product revision, product testing, finished products. The subjects of this study were 34 students of class XII SMK Negeri 1 Singosari, material experts from one Civil Engineering Lecturer at State University of Malang and media experts from one Lecturer in Civil Engineering, State University of Malang. The results obtained from this development research are Android-based learning media on the subject of Implementation and Supervision of Construction and Building Works with specifications containing (1) Application Introduction Page, (2) Main Menu, (3) Competence, (4) Material, (5) ) Learning Videos, (6) Practice Questions, (7) User Guide, (8) Developer Profile. The results of the research for the feasibility test show that the Development of Learning Media for Implementation and Supervision of Building Construction Work of Android-Based Mobile Learning for Class XII Students in Construction and Property Business at SMK Negeri 1 Singosari is classified as quite valid and can be distributed.
\end{abstract}

Keywords: R\&D, Android, Android Application, Mobile Learning, P3KG 


\section{PENDAHULUAN}

\subsection{Latar Belakang Masalah}

SMK merupakan jenjang Pendidikan yang menkhususkan Peserta didiknya menekuni bidang kerja tertentu dari pelajaran produktif bersamaan dengan Pendidikan Akademik. Salah satu bidang keahlian SMK yaitu Teknologi dan Rekayasa yang mana di dalam bidang tersebut terdapat Kompetensi Keahlian Bisnis Konstruksi dan Properti (BKP). Bidang keahlian Bisnis Konstruksi dan Properti (BKP) adalah sebuah bidang Kompetensi Keahlian yang ada di Indonesia yang mana menekuni lapangan pekerjaan di bidang Struktur Bangunan.

Mata Pelajaran Pelaksanaan dan Pengawasan Pekerjaan Konstruksi Gedung (P3KG) adalah materi pembelajaran yang memahami tentang Konsep perancangan struktur bangunan dan terdiri atas Kelas Teori maupun Praktikum yang bedasarkan Kompetensi Inti 3 / KI 3 (Pengetahuan) dan Kompetensi Inti 4 / KI 4 (Ketrampilan). Cakupan KI 3 yaitu Memahami, mengimplementasi, menganalisa, dan evaluasi tentang pengetahuan factual, conseptual, dasar operasional, dan metacognitif bedasarkan dengan bidang dan cakupan kerja di bidang Konstruksi dan Properti. Sedangkan Cakupan KI 4 yaitu melakukan tugas spesifik dengan mempergunakan sebuah alat, informasi, dan panduan pekerjaan yang biasa dilakukan di lalapan serta memecahkan masalah sesuai dengan bidang kerja Bisnis Konstruksi dan Properti.

Bedasarkan pengalaman Penulis pada saat menempuh Kajian dan Praktik Lapangan (KPL) di SMK terdapat bahwa siswa biasanya kurang mampu mengerti konsep materi maupun konsep praktikum yang disampaikan oleh Mahasiswa KPL maupun Guru Pamong pada saat kegiatan belajar berlangsung. Mulyati (2013) menegaskan, sebagai simpulan dari istilah Understanding yang diartikan sebagai penangkapan peserta didik pada saat memahami sebuah materi pembelajaran yang dipelajari. Seorang siswa dikatakan memahami materi apabila ia dapat memberikan penjelasan atau memberi uraian lebih detail tentang materi tersebut dengan menggunakan gaya kata-katanya sendiri.

Menurut Survey Pusat Penelitian Dan Pengembangan Aplikasi Informatika Dan Informasi Komunikasi Publik pada tahun 2017 Kepemilikan Smartphone pada jenjang Pendidikan SMA/SMK secara Individu, yaitu 79,56\%. Dari paparan fakta tersebut, dapat disimpulkan bahwa ketergantungan peserta didik pada smartphone sangat banyak. Namun, penggunaan pada jenjang tersebut lebih cenderung digunakan untuk Hiburan yang dapat menghambat proses pembelajaran peserta didik pada saat sekolah maupun pada saat diluar sekolah. Hal ini mendorong Penulis ingin mengembangkan produk Media Pembelajaran berbentuk aplikasi berbasis Mobile Learning di dalam Smartphone pada system operasi Android. Dengan media pembelajaran yang relevan menurut perkembangan teknologi, Peserta didik diharapkan bisa mudah mengakses dan mempelajari materi dimana saja dan kapan saja. Bedasarkan data faktual diatas, permasalahan ini mendorong penulis untuk melaksanakan pengembangan produk media pembelajaran berbentuk aplikasi pada sistem android.

\subsection{Tujuan Penelitian}

Bedasarkan paparan fakta diatas pada latar belakang, maka tujuan dilaksanakannya penelitian dan pengembangan ini yaitu:

a. Menghasilkan Produk Media Pembelajaran Pelaksanaan dan Pengawasan Pekerjaan Konstruksi Gedung (P3KG) Berbasis Mobile Learning untuk Platform Android

b. Menguji coba pada Peserta Didik pada SMK Negeri 1 Singosari agar Mengetahui Relevansi Produk Media Pembelajaran Pelaksanaan dan Pengawasan Pekerjaan Konstruksi Gedung (P3KG) Berbasis Mobile Learning untuk Platform Android

\subsection{Metode Penelitian}

Metode yang digunakan oleh peneliti yaitu R \& $\mathrm{D}$ (Research and Development). Menurut Budiyono (2017:8) Metode Research \& Development (R\&D) merupakan metoda penelitian yang menghasikan gagasam produk pada bidang keahlian tertentu, yang mana produk sampingan tertentu dan memiliki efektifitas dari sebuah produk tersebut. Aplikasi ini dibuat dari model model pengembangan Borg and Gall yang bedasarkan modifikasi dari Sugiyono (2014) lalu Metode ini dimodifikasi dengan sederhana oleh pengembang menjadi 6 langkah meliputi 1) analisis kebutuhan dan pengumpulan data 2) desain produk 3) Validasi 4) Revisi Produk Awal 5) Pengujian produk 6) Produk Jadi

\section{KAJIAN PUSTAKA}

Media Pembelajaran sebagai sarana secara nyata berbentuk berupa teks, gambar, maupun audio yang mempunyai pesan instruksional dan dikomunikasikan secara langsung. Kemp (1975:15) mendemokan proses komunikasi pembelajaran sebagai berikut :

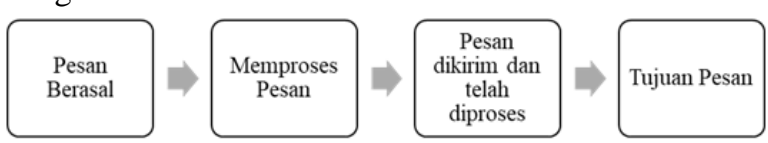

\section{Gambar 1. Proses KomunikasiSecaraLangsung oleh Kemp (1975:15)}

Menurut Mayer (dalam Putri KumalaDewi, 2018) tujuan media pembelajaran adalah menciptakan meaningful learning 'pembelajaran bermakna' karena dengan adanya suatu instrument pengantar pesan-pesan pembelajaran, pembelajaran akan mengalami aktivitas kognitif dan psikomotorik dalam pembelajaran. Dapat disimpulakan bahwa 
fungsi dan tujuan media pembelajaran adalah untuk memfasilitasi proses belajar agar dapat meningkatkan kualitas belajar yang lebih baik.

Tri \&Anteng (2013) mendefinisikan m-learning sering didefinisikan sebagai perangkat komputasi mobile. Mobile Learning juga merupakan penyampaian bahan pembelajaran elektronik pada perangkat telefon genggam sehingga dapat diakses dari mana saja dan kapan saja. Namun, secara umum dapat didefinisikan sebagai perangkat apapun yang berukuran cukup kecil, dapat bekerja sendiri, bias dibawa setiap waktu dalam kehidupan sehari-hari, dan yang dapat digunakan untuk beberapa bentuk kegiatan pembelajaran. Perangkat kecil ini dapat dilihat sebagai alat untuk mengakses konten pembelajaran, baik disimpan secara local pada device maupun dapat dijangkau melalui internet. Perangkat ini juga bias dijadikan alat untuk berinteraksi dengan orang lain, baik melalui suara, maupun saling bertukar pesan tertulis, gambar diam dan gambar bergerak.

Bedasarkan dari Konteksnya, Pembelajaran berbasis Video menurut Pappas. Dkk (2016) menyatakan "Video Based Learning which defined as the learning process of acquiring defined knowledge, competence, and skills with the systematic assistance of video resources." Penulis dapat menyimpulkan bahwa Pembelajaran berbasis video adalah proses pembelajaran untuk memperoleh pengetahuan, kompetensi, dan keterampilan yang ditentukan dengan sistematis berbantuan dari fasilitas video atau gambar bergerak. Sedangkan bedasarkan definisi teknis pembetuk video adalah gabungan dari audio dan visual, menurut Nadheak, dkk (2020) Menyatakan "Video is a recording of an image or a real object that is accompanied by sound or often referred to as audiovisual media that displays both images and sound. This media is very often used in the teaching and learning process because it can foster students' interest in learning, where students can simultaneously listen and see things even though objects that are seen and heard are not directly from the primary source, but through intermediary media such as TV, laptops, computers, or mobile phone." Penulis dapat menyimpulkan bahwa Video adalah rekaman suatu gambar atau benda nyata yang disertai dengan suara atau sering disebut sebagai media audio visual yang menampilkan gambar dan suara. Media ini sangat sering digunakan dalam proses belajar mengajar karena dapat menumbuhkan minat siswa Pembelajaran, dimana siswa dapat secara bersamaan mendengarkan dan melihat benda meskipun benda yang dilihat dan didengar tidak langsung dari sumber utama, tetapi melalui perantara media seperti TV, laptop, komputer, atau ponsel.

Dari pendapat yang telah dipaparkan diatas, penulis dapat menarik kesimpulan bahwa Pembelajaran berbasis video merupakan sekumpulan materi-materi pembelajaran meliputi apapun objek yang digunakan untuk kebutuhan demonstrasi dalam menyampaikan isi pesan materi yang terkandung bedasarkan matapelajaran maupun silabus untuk memperoleh pengetahuan, kompetensi, maupun keterampilan dan dikemas menjadi satu rangkaian video yang dihasilkan melalui proses perencanaan, pengambilan gambar, hingga penyuntingan.

Mata pelajaran Pelaksanaan dan Pengawasan Pekerjaan Konstruksi Gedung (P3KG) di jurusan Bisnis Konstruksi dan Properti pada SMK Negeri 1 Singosari merupakan matapelajaran baru yang telah direvisi pada tahun 2018. Mata pelajaran ini mempunyai alokasi waktu 144 Jam pelajaran tiap semesternya. Mata pelajaran ini digolongkan sebagai jam produktif. Mata pelajaran pelajaran Pelaksanaan dan Pengawasan Pekerjaan Konstruksi Gedung (P3KG) di SMK Negeri 1 Singosari menggunakan kurikulum 2013, Tujuan kurikulum mencakup empat aspek kompetensi, yaitu (1) aspek kompetensi sikap spiritual, (2) sikap sosial, (3) pengetahuan, dan (4) keterampilan. Mata pelajaran ini mempunyai 2 kompetensi, yaitu Kompetensi 3 (KI3) dan Kompetensi 4 (KI4).

Tabel 1. Deskripsi Kompetensi Mata Pelajaran

\begin{tabular}{|c|c|c|c|}
\hline No & $\begin{array}{l}\text { Kompetensi } \\
\text { Dasar }\end{array}$ & $\begin{array}{l}\text { Indikator } \\
\text { Pencapaian } \\
\text { Kompetensi }\end{array}$ & $\begin{array}{l}\text { Materi } \\
\text { Pokok }\end{array}$ \\
\hline 1 & $\begin{array}{l}\text { 1.1.Mengevaluasi } \\
\text { hasil pelaksanaan } \\
\text { pekerjaan beton } \\
\text { bertulang }\end{array}$ & $\begin{array}{l}\text { 1.Mengecek (C5) } \\
\text { hasil pelaksanaan } \\
\text { pekerjaan beton } \\
\text { bertulang sesuai } \\
\text { metakognitif } \\
\text { 2. Menilai (C5) } \\
\text { hasil pelaksanaan } \\
\text { pekerjaan beton } \\
\text { bertulang sesuai } \\
\text { metakognitif }\end{array}$ & $\begin{array}{l}\text { Pendahuluan } \\
\text { Perencanaan } \\
\text { Mix Design } \\
\text { Menghitung } \\
\text { Perencanaan } \\
\text { Mix Design } \\
\text { Pelaksanaan } \\
\text { Pekerjaan } \\
\text { campuran } \\
\text { beton }\end{array}$ \\
\hline 2 & $\begin{array}{l}\text { 2.1. Membuat } \\
\text { laporan hasil } \\
\text { evaluasi } \\
\text { pekerjaan beton } \\
\text { bertulang }\end{array}$ & $\begin{array}{l}\text { 1. Merancang }(\mathrm{P} 2) \\
\text { hasil evaluasi } \\
\text { pelaksanaan } \\
\text { pekerjaan beton } \\
\text { bertulang } \\
\text { 2.Membuat }(\mathrm{P} 2) \\
\text { laporan hasil } \\
\text { evaluasi } \\
\text { pelaksanaan } \\
\text { pekerjaan beton } \\
\text { bertulang }\end{array}$ & $\begin{array}{l}\text { Evaluasi uji } \\
\text { kuat tekan } \\
\text { beton, dan } \\
\text { Pembuatan } \\
\text { Laporan }\end{array}$ \\
\hline
\end{tabular}

\subsection{Analisis Data}

Analisis data yang penulis gunakan merupakan statistik deskriptif dengan hitungan dari presentasi skor di setiap item. Perhitungan tersebut dipakai untuk mengkategorikan validitas dari media pembelajaran yang dihasilkan. Bedasarkan Riduwan (2012: 29) Perhitungan yang dipakai adalah: $V \frac{\Sigma X 1}{\Sigma X 0} X 100 \%$

$\mathrm{V}=$ Tingkatan Validitas

$\sum \mathrm{X} 1=$ Julmah nilai jawaban dari validator

$\sum \mathrm{X} 0=$ jumlah nilai yang diharapakan 


\subsection{HASIL PENGEMBANGAN}

Hasil yang diperoleh dari penelitian pengembangan ini adalah media pembelajaran berbasis android pada mata pelajaran Pelaksanaan dan Pengawasan Pekerjaan Konstruksi dan Gedung. Aplikasi ini hanya dapat dijalankan pada Smartphone berbasis Sistem Operasi Android yang efektif digunakan sebagai media belajar yang sesuai dengan kebutuhan di SMK Negeri 1 Singosari. Maka didapatkan hasil meliputi (1) Halaman Pengantar Aplikasi, (2) Main Menu, (3) Kompetensi, (4) Materi, (5) Video Pembelajaran, (6) Latihan Soal, (7) Panduan Penggunaan, (8) Profil Pengembang.

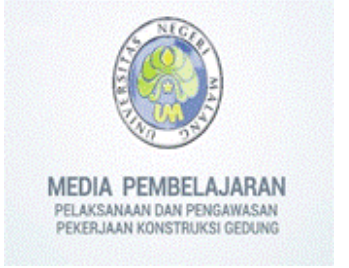

Gambar 2. Halaman Pengantar

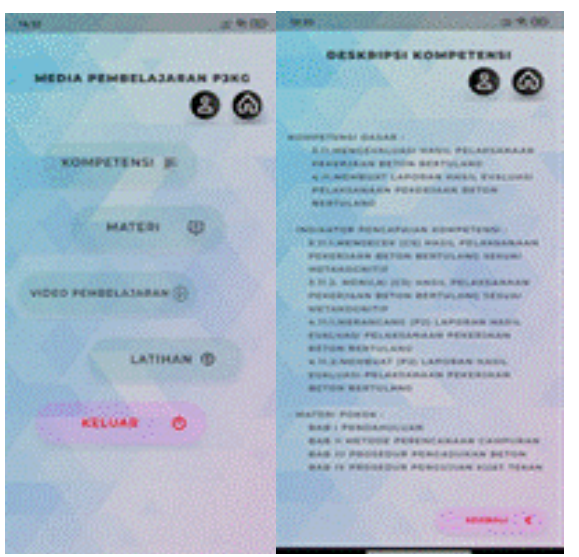

Gambar 3. Menu Utama dan Deskripsi Kompetensi

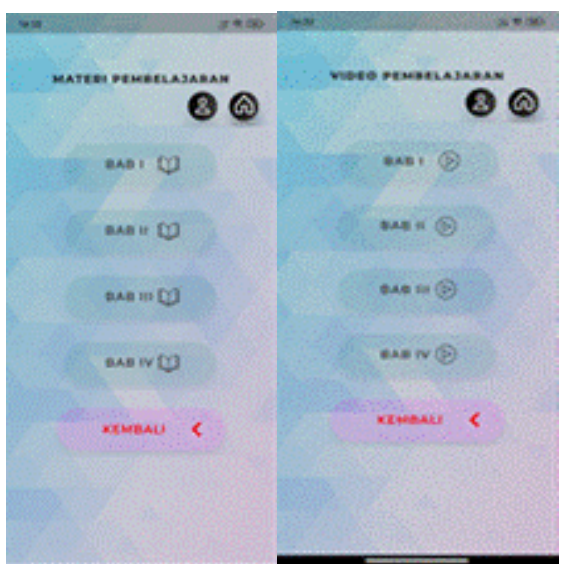

Gambar 4. Menu Materi dan Video Pembelajaran

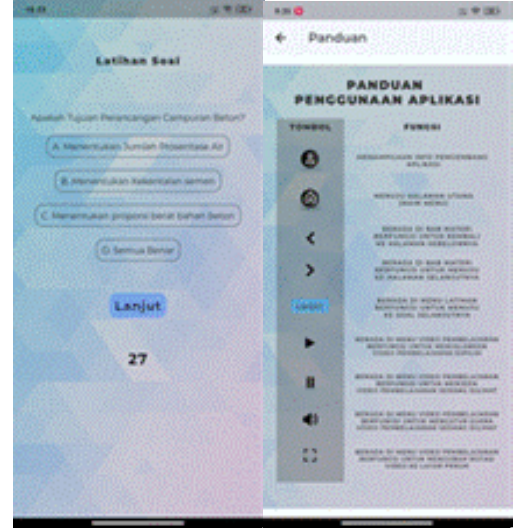

Gambar 5. Menu Latihan soal dan Panduan Penggunaan

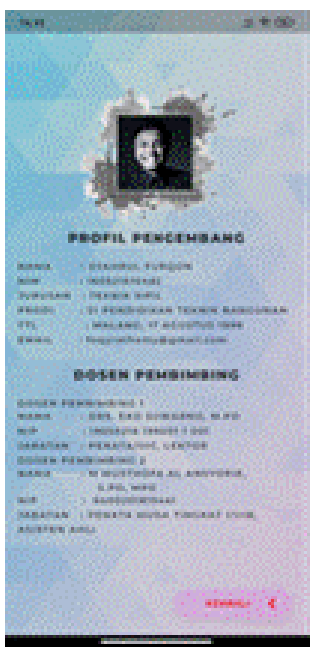

Gambar 6. Menu Profil Pengembang

\subsection{HASIL VALIDASI}

Subjek penelitian ini diujicobakan dengan kelompok sebanyak 34 orang (satu kelas). Untuk data hasil uji coba produk berbentuk data kuantitatif.Hasil validasi oleh validator ahli materi, aspek penilaian pada desain pembelajaran didapatkan dengan skor $81,25 \%$ dan termasuk pada klasifikasi cukup valid yang mana desain pembelajaran tersebut bisa digunakan namun perlu adanya revisi. Selanjutnya, pada aspek penilaian pembelajaran dan strategi pembelajaran didapatkan dengan skor $75 \%$ yang mana aspek pembelajaran dan strategi pembelajaran pada media pembelajaran ini cukup valid dan dapat digunakan namun perlu adanya revisi, dan terakhir yaitu kesesuaian materi pada video pembelajaran didapat $87,50 \%$ yang mana dapat dikategorikan sangat valid, maka dari itu materi pada video pembelajaran dapat digunakan dan tanpa adanya revisi.

Berdasarkan hasil perhitungan validitas media diperoleh persentase skor untuk aspek fungsionalitas yaitu $85 \%$ yang mana pada aspek ini dikategorikan cukup valid dan dapat dilanjutkan namun perlu adanya revisi. Aspek reabilitas didapatkan dengan skor $91,67 \%$ yang mana pada aspek ini 
dikategorikan sangat valid dan tidak perlu adanya revisi. Aspek usabilitas didapatkan dengan skor 93,75\% yang mana pada aspek ini dikategorikan sangat valid dan tidak perlu adanya revisi. Aspek efisiensi didapatkan dengan skor $87,5 \%$ yang mana pada aspek ini dikategorikan sangat valid dan tidak perlu adanya revisi. Aspek pemeliharaan didapatkan dengan skor $100 \%$ dapat dikategorikan sangat valid dan tidak perlu adanya revisi. Untuk aspek portabilitas dan aspek multimedia didapatkan dengan skor $81,25 \%$ yang mana dikategorikan cukup valid dan dapat dilanjutkan namun adanya revisi.

Berdasarkan hasil perhitungan didapatkan persentase skor dari responden media pembelajaran berbasis aplikasi android pada aspek penggunaanya yaitu $84,87 \%$ yang mana pada hasil ini dikategorikan cukup relevan. Pada aspek kemanfaatan media pembelajaran ini didapat persentasi $80,88 \%$ yang mana pada hasil ini dikategorikan cukup relevan. Pada aspek kesesuaian media pembelajaran ini didapat hasil $80,15 \%$ yang mana pada hasil ini dikategorikan cukup Relevan, maka dari itu kesesuaian media pembelajaran dapat digunakan namun perlu diadakan revisi bedasarkan kajian dari validator materi maupun media.

\section{KESIMPULAN}

Pengembangan media pembelajaran ini dapat digunakan dalam pembelajaran karena meningkatkan pemahaman siswa. Hal itu dibuktikan dengan hasil perhitungan Dari keseluruhan Validitas didapatkan rata-rata validitas materi $79,6 \%$ dan validitas media $88,63 \%$ pada media pembelajaran ini dikategorikan cukup valid dan dapat disebarkan. Produk media pembelajaran ini hanya terbatas pada materi sub bab "perancangan dan praktikum pembuatan beton pada silinder". Oleh sebab itu, disarankan agar mampu dikembangkan pada materi lainnya. Pengembangan media pembelajaran ini hanya terbatas pada tahapan Uji Coba Produk dengan 34 subjek penelitian, sehingga disarankan untuk peneliti selanjutnya melakukan kajian dan revisi produk untuk mengetahui tingkat kualitas produk yang berguna untuk siswa SMK di Indonesia sesuai dengan keperluan peningkatan pemahaman siswa.

\section{PUSTAKA}

Aziz, M. M., \& Guntara, R. G. 2019. "Pembangunan Aplikasi M-Delivery $\mathrm{Di} \mathrm{Pt}$ Pos Indonesia (Persero) Wilayah Bandung Berbasis Android" Doctoral dissertation, Universitas Komputer Indonesia.

Cahyani, V. D. (2020). Perancangan Aplikasi Penerimaan Peserta Didik Baru (Ppdb) Pada Smk Yaditama Sidomulyo Berbasis Web. Jurnal Informatika dan Rekayasa Perangkat Lunak, 1(1), 120-126.

Dhir, Rajeev. 2019. "Interactive Media, How Does Interactive Media Work?”. (Online), (https://www.investopedia.com/terms/i/interactiv e-media.asp). Diakses 12 Februari 2020

EkaLegya. 2018. "Pengembangan Dan Analisis Media Pembelajaran Perakitan Komputer Berbasis Augmented Reality Untuk Platform Android Di Smk Ypkk 1 Sleman”. (Online), (https://eprints.uny.ac.id/29187/) , diakses 11 November 2020

Giannakos, M. N., Sampson, D. G., \& Kidziński, Ł. (2016). Introduction to smart learning analytics: foundations and developments in video-based learning. Smart Learning Environments, 3(1), 19.

Haider, dkk. 2018. "Pengembangan Aplikasi Modul Pembelajaran Desain Grafis Berbasis Android". (Online),

(https://ojs.unm.ac.id/mediaTIK/article/view/827 9), diakses 11 November 2020

Husna, 2018. Validitas Pengembangan Aplikasi Promosi Produkusaha Mikro, Kecil, Dan Menengah (Umkm) Kota Bukittinggi. (Online), (http://jurnatik.amikroyal.ac.id/index.php/amikro yal/article/view/81/63). Diakses pada 11 November 2020

Imam, Azhari. 2012. Proses Pemodelan Software Dengan Metode Waterfall Dan Extreme Programming: Studi Perbandingan. (Online), (http://jurnal.stmikelrahma.ac.id/assets/file/Imam \%20Fahrurrozi,\%20Azhari\%20SN_stmikelrahm a.pdf). Diakses pada 1 Maret 2020

Irmanto. 2018. "Pengembangan Media Pembelajaran Berbasis Unity 3d untuk Platform Android Pada Pembelajaran Gambarteknik Kelas X Di Smk Nasional Berbah". (Online), (http://eprints.uny.ac.id/60502/1/Naskah\%20Tas \%20Irmanto.pdf), diakses 8 Februari 2020

Kominfo. 2017. "Survey penggunaan TIK serta implikasinya terhadap Aspek Sosial Budaya Masyarakat".

(Online), (https://balitbangsdm.kominfo.go.id/?mod=publi kasi\&a=dl\&page_id=360\&cid=9\&download_id= 187), diakses 8 Februari 2020

Lailela, S. N., \& Kusumadiarti, R. S. (2018). Pengukuran Kualitas Perangkat Lunak Aplikasi Sisfo_Nilai Di Politeknik Piksi Ganesha Berdasarkan ISO 9126. Jurnal E-Komtek (Elektro-Komputer-Teknik), 2(2), 84 - 100. https://doi.org/10.37339/e-komtek.v2i2.96

Mulyati, 2013. "Peningkatan Kemampuan Pemahaman Dan Representasi Matematis Siswa Sma Melalui Strategi Preview-Question-ReadReflect-Recite-Review: Kuasi Eksperimen Pada Siswa Sma Di Kabupaten Indramayu". Universitas Pendidikan Indonesia.

Nadeak, B., \& Naibaho, L. (2020). Video-Based Learning on Improving Students' Learning Output. PalArch's Journal of Archaeology of Egypt/Egyptology, 17(2), 44-54. 
Noviani, N., Herdiansyah, M. I., \& Diana, D. (2020). Analisis Kualitas Perangkat Lunak Penilaian Kurikulum 2013 Menggunakan Standar ISO/IEC 9126-1: 2001. Jurnal Pengembangan Sistem Informasi dan Informatika, 1(1), 34-49.

Nurseto, Seto. 2011. "Membuat Media Pembelajaran yang Menarik". (Online), (https://journal.uny.ac.id/index.php/jep/article/vi ew/706/570). Diakses pada 16 Februari 2020

Oka, Gde, 2017. Media dan Multimedia Pembelajaran. Edisi.1, Cetakan 1. Yogyakarta : Deepublish,

Prasasti, I. H., Nanda, A. P., Isnandar, S., \& Pramono, D. E. H. Pengembangan Aplikasi ELearning Pada Smk Pelita Bangun Rejo.

Putri, Nia, 2018. Media Pembelajaran Bahasa, Aplikasi Teori Belajar dan Strategi Pengoptimalan Pembelajaran. Malang: UB Press

Reiser, Gagne, 1983. "Selecting Media for Instruction". New Jersey: Educational Technology Publications, Inc.,

Risna, Hanifah. 2017. "Analisis Kemampuan Pemahaman Matematis Siswa Smp Pada Materi Bangun Ruang Sisi Datar" Karawang: Universitas Singaperbangsa.

Saputro, Budiyono. 2017. Manajemen Penelitianpengembangan( Research \& Development )Bagi Penyusun Tesis Dan Disertasi.Yogyakarta : Aswaja Pressindo

Saroh, Siti, 2019. Tutorial Membuat Media Pembelajaran 4.0. Cetakan Pertama. Surabaya: CV Pustaka MediaGuru

Sugiyono. (2014). Metode penelitian pendidikan (pendekatan kuantitatif, kualitatif, dan R\&D). Bandung: Alfabeta.

Sukoco, Agus. 2010. Penggunaan Standard ISO 9126 Untuk Mengevaluasi Keefektifan Perangkat Lunak.

(Online), (http://jurnal.ubl.ac.id/index.php/explore/article/v iew/336). Diakses pada 1 Maret 2020

Susilana, Rudi, dan Riyana, Cepi. 2009. Media Pembelajaran: Hakikat, Pengembangan, Pemanfaatan dan Penilaian. Bandung: CV. Wacana Prima.

Traxler, John, Kukulska-Hulme. 2005. "Evaluating Mobile Learning: Reflections on Current Practice". (Online), (http://oro.open.ac.uk/12819/1/mlearn05_Traxler \%26Kukulska Hulme.pdf), diakses 9 Februari 2020

Undang Undang Republik Indonesia Nomor 20 Tahun 2003 bab 12 pasal 45 ayat 1. (Online), (http://hukum.unsrat.ac.id/uu/uu_20_03.htm), diakses 7 Februari 2020.

Universitas Negeri Malang. 2017. Pedoman Penulisan Karya Ilmiah: Skripsi, Disertasi, Artikel, Makalah, Tugas Akhir, Laporan Penelitian. Malang: Universitas Negeri Malang. 